\title{
When normal is normative: The ethical significance of conforming to reasonable expectations
}

\author{
Hugh Breakey ${ }^{1}(\mathbb{0}$
}

Accepted: 24 January 2022 / Published online: 1 March 2022

(c) The Author(s) 2022

\begin{abstract}
People give surprising weight to others' expectations about their behaviour. I argue the practice of conforming to others' expectations is ethically well-grounded. A special class of 'reasonable expectations' can create prima facie obligations even in cases where the expectations arise from contingent pre-existing practices, and the duty-bearer has not created them, or directly benefited from them. The obligation arises because of the substantial goods that follow from such conformity-goods capable of being endorsed from many different ethical perspectives and implicating key moral factors such as consent, fairness, respect, autonomy, and reciprocity. Given the innumerable situations where such expectations can arise, their ethical significance is critical both practically and philosophically.
\end{abstract}

Keywords Expectations $\cdot$ Conformity $\cdot$ Legitimate expectations $\cdot$ Descriptive norms $\cdot$ Hope-casts

Expectations about behaviour matter. Everyday life abounds with recommendations that we should temper, curb, lower, match, manage, live up to, or raise expectations. Such expectations touch on almost every part of our social existence: commercial arrangements, intimate relationships, professional standards, coordinating conventions, joint actions, collective goods, social ritual, etiquette, proxemics (including personal space), verbal and nonverbal communication, the use of public and quasipublic spaces, and more.

Yet what is the moral status of such expectations? What more, ethically speaking, is added to a practice or action when it is expected? If person $\mathrm{X}$ expects person $\mathrm{Y}$ will

Hugh Breakey

h.breakey@griffith.edu.au

1 Institute for Ethics, Governance \& Law, Law Futures Centre, Griffith University, 170

Kessels Road, Nathan, Queensland, Australia 
perform action $\mathrm{A}$ in situation $\mathrm{S}$, then does that give $\mathrm{Y}$ an obligation to $\mathrm{A}$ in $\mathrm{S}$ ? I will contend - at least for certain types of 'reasonable expectations' - that Y can indeed possess a substantial, if defeasible, obligation to A in such a case.

The forthcoming argument aims to show that an action can be such that, because it is expected, a person has a defeasible obligation to conform to it. Phrased in general terms, that claim may be unsurprising. ${ }^{1}$ However, the following analysis aims to substantiate four further theses. First, I aim to provide a rich account of the many reasons why expectations can be morally significant - showing that expectations can create duties even in cases where commonplace routes to justifying duties (such as through direct reciprocity or tacit consent) are not present. Second, this account allows us to distinguish the types of 'reasonable' expectations capable of creating moral obligations. This provides preliminary guidance to agents wanting to understand when and how expectations should factor into their practical ethical decision-making. (Or, at least, to lay the groundwork for developing more situation-specific guidance.) Third, I argue that the obligations arising in this way can be surprisingly weighty-even perfect, directed obligations. Fourth, as well as making a general 'common-sense ethics' case for respecting certain types of expectations, I show how the nature of reasonable expectations implicates key factors central to mainstream ethical perspectives. Whatever one's theoretical commitments, expectations matter morally.

My argument proceeds as follows: Sect. 1 canvasses the existing scholarship on expectations-infused obligations, before Sect. 2 sketches four illustrative cases to ground the ensuing discussion. Section 3 notes relevant empirical research exploring expectations and obligations. Section 4 describes the ethical goods that can be achieved by conforming to expectations. Drawing on this analysis, Sect. 5 sets down five criteria for what I term 'reasonable expectations' $\left(\right.$ expectations $\left.{ }^{R}\right)$. Section 6 then considers four mainstream ethical theoretical approaches, as well as a more general ethics, in justifying an obligation to conform to expectations ${ }^{\mathrm{R}}$. Yet this obligation is only prima facie. As Sect. 7 relates, even expectations ${ }^{\mathrm{R}}$ may possess worrying properties that may defeat the imposition of an obligation.

Two definitional notes. The word 'expectation' is ambiguous (Miceli \& Castelfranchi, 2002; Provis, 2011, 56), potentially referring to a prediction, a desired outcome, or a moral obligation. In Sect. 5 I will describe a specific class of 'reasonable expectations', but otherwise an 'expectation' refers to a prediction.

I also employ the term 'descriptive norm': A descriptive norm occurs when most people (or, at least, people like Y) historically do A in S-and this can ground the prediction that $\mathrm{Y}$ will $\mathrm{A}$ in $\mathrm{S}$. (In contrast, a prescriptive norm occurs when there is an explicit social belief that all people (like Y) should A in S.)

\footnotetext{
${ }^{1}$ There is a deeper conceptual query here, analogous to the question legal philosophy raises with respect to law: Can expectation as such provide a content-independent, if defeasible, moral reason to conform? My answer is a qualified yes, but I must frankly acknowledge the many defeating considerations (see Sects. 5 and 7) that prevent straightforwardly moving from expectation to obligation.
} 


\section{Existing justifications for expectations as obligations}

The literature has previously explored several ways obligations arise from or with expectations.

A prefatory case occurs when $\mathrm{Y}$ and $\mathrm{X}$ share a joint goal that can be solved by a coordinating convention where they both $\mathrm{A}$ in $\mathrm{S}$. In the case of Lewisian conventions, such as informal road rules, both $\mathrm{Y}$ and $\mathrm{X}$ have reason to want to coordinate their behaviour, and settled expectations allow them to do so (Lewis, 2002/1969). While this arrangement provides rational reason for subjects to conform, it intuitively seems conformity is also morally required. Lewis $(2002 / 1969,98)$ presumes 'other things being equal, that one ought to do what answers to others' preferences, especially when they may reasonably expect one to do so.' While I will offer direct support to Lewis' presumption, other scholars have sought to supply the moral content in this and other expectations-infused cases through other devices.

First, an appeal might be made to fairness and direct reciprocity. In cases where $\mathrm{Y}$ has directly benefited from X previously A-ing in S, Y's subsequent duty to A can be based on direct reciprocity (such as through the 'principle of fairness' (Boran, 2016)).

Second, in cases where $\mathrm{Y}$ herself has knowingly (and perhaps intentionally) created X's expectation that $Y$ will A in S, Y's responsibility for knowingly eliciting X's expectation, and therefore encouraging $\mathrm{X}$ to rely on Y's performance of A, can be argued to justify Y's obligation to A (Scanlon, 1990).

Third, some scholars have taken a further step, and argued that the intentional creation of expectations can work as a type of tacit consent (or 'implied agreement'/'implicit promise'/'quasi-contract'), thus justifying the ensuing duties on the basis of consent (Kershnar, 2014).

These accounts aren't mutually exclusive, and indeed are often integrated, and combined with Lewisian conventions and other practices where agents have selfinterested reasons to comply (Castelfranchi \& Giardini, 2003; Tummolini et al., 2013). This makes sense, as self-interested reasons for compliance make it more reasonable to assume the person consents to the obligation.

It is not my purpose to argue against these accounts. None of them presume to comprehensively cover all expectations-based obligations, so they are broadly compatible with what follows. ${ }^{2}$ Implicit promise, direct reciprocity, and intentional creation of expectations all have at least prima facie moral significance, and so in cases where they are present, they will, pro tanto, provide reason for an obligation. However, I will argue that such factors by no means exhaust the ways in which expectations can give rise to obligations.

The same point follows for accounts of 'legitimate expectations' as they arise in law, with Rawls' work perhaps the best known contemporary treatment. ${ }^{3}$ Speaking broadly, for Rawls legitimate expectations worthy of respect and protection arise in cases where a policy or rule is enacted by a legitimate authority, when that pol-

\footnotetext{
${ }^{2}$ That said, I do argue against accounts of tacit consent that explicitly claim expectation and descriptive norms cannot justify obligations: (Kershnar, 2014, 261).

${ }^{3}$ The argument below draws explicitly on several philosophers of law, particularly Jeremy Bentham and Lon Fuller.
} 
icy or rule is itself justified (ultimately through Rawls' principles of justice), and when citizens have been encouraged to rely upon the policy or rule (Rawls, 1971, 206-213, 273-277; Brown, 2012). Again, my intent is not to contest Rawls' account, as these three factors doubtless give special moral weight to citizens' expectations. Rather, I will argue that expectations can have moral force beyond the specific factors Rawls enumerates, and-moreover-outside the legal-cum-institutional context upon which he focuses.

\section{Four illustrative cases}

To keep things concrete, my analysis aims to cover the following illustrative cases (drawn from Ellickson, 1993; Dana et al., 2006; Breakey, 2011; Provis, 2011; Heintz, Celse et al., 2015):

1. Social practices ('Basketball'): Yvonne arrives at a local basketball court. Her friend, Xavier, explains the informal practices governing which groups can access the court and play with other groups. If Yvonne goes onto the courts, does she have a moral obligation based on Xavier's (and others') expectations that she will conform to these practices?

2. Expected distributions ('Inheritance'): Xavier and Yvonne know that Yvonne will soon inherit their mother's wealth. There is a strong social expectation in their community that Xavier, as Yvonne's younger brother, is entitled to one-third of Yvonne's inheritance. Does Xavier's long-standing expectation that he will receive this sum contribute to an obligation that Yvonne should share one third of the inheritance with him?

3. Commercial scripts ('Waiter'): A waiter in a local café, Xavier, ushers the new patron, Yvonne, to her table and provides her with the menu. Yvonne knows Xavier will expect her to begin reading the menu and arrive at a decision about what to order, or about what further information she needs to make that choice. Does Yvonne have an obligation to conform to his expectation (as distinct from, say, mooching on her smartphone)? Let's add a more context-dependent question referring to a case where tipping is the local norm ("Waiter/Tipping"'), asking whether, when Yvonne finishes her meal, she has a duty to tip Xavier?

4. Relationships ('Secrecy'): Late one night, Xavier shares a personal anecdote with his close friend Yvonne about an embarrassing but harmless incident. Within their local community, such confidences are always kept. Does Xavier's expectation mean Yvonne possesses a moral obligation not to reveal the story to others?

In each illustrative case, $\mathrm{X}$ predicts that $\mathrm{Y}$ will conform to the pre-existing practice by doing A. Let's stipulate that in no case has Y explicitly agreed to do A, benefited previously from $\mathrm{X}$ doing A, or consciously encouraged X's belief that she will A. Note further that in at least two of these cases, tacit consent can't plausibly ground the duty. For example, if Inheritance is knitted into a larger social practice of resource distribution, then there could be no way for Y to unilaterally remove her moral obli- 
gations to X. Likewise, in Basketball there seems no option for Y to declare she is not participating in the norm. She can only avoid the obligations by staying off the court.

Indeed, tacit consent doesn't provide entirely fulfilling answers even to cases like Secrecy and Waiter/Tipping. At first, it might seem that tacit consent must play a role, insofar as Y could - at the opportune moment — divest herself of the obligations by a unilateral declaration, asserting that she doesn't tip, and won't keep secrets (for the tipping case, see Kershnar 2014, 263-264). Yet such a declaration may not fully absolve any obligation. $\mathrm{X}$ the waiter might object: 'I depend on these tips to make my living.' And X the secret-teller might complain, 'I thought you were my friend!' But let's arguendo accept that the declaration made at the opportune moment fully absolves any obligation. Note that this 'at the opportune moment' clause refers to $Y$ 's declaration happening before actions have been taken by $X$ in reliance on his expectations, and that in both cases the duty is annulled precisely by removing $X$ 's expectations (or, if $\mathrm{Y}$ is then asked to leave in Waiter, then the duty is avoided by $\mathrm{Y}$ exiting the expectation-triggering situation). Given the central role of expectation in determining if, when, and how the duty can be annulled, we might therefore be curious about whether it is the expectations themselves grounding the duties. This curiosity might be heightened by considering cases where $\mathrm{Y}$ is unaware of (or has simply forgotten) the norm at the time the reliance is created, but is informed before the obligation must be performed. If our intuition is that $\mathrm{Y}$ remains obliged to pay the standard gratuity (if she can), or to keep the secret, then devices like tacit consent or intentional creation cannot be justifying the obligation. (In his implicit promising account of tipping, Kershnar $(2014,264)$ bites this bullet, denying there can be any obligation in such cases).

Summing up, the four illustrative cases suggest there is more morally going on than can be explained by mechanisms like tacit consent and direct reciprocity. In what follows, I aim to supply plausible ethical reasons why in all four cases - and myriad analogous ones - it is plausible to think that Yvonne has an obligation to Xavier based on his expectations about her behaviour, irrespective of the presence or otherwise of direct reciprocity, tacit consent, or the intentional creation of expectations.

\section{Social psychology on expectations and felt obligation}

There are several social-psychological studies on expectations and obligations that can inform this enquiry. ${ }^{4}$

Conceptually, prediction and desire combine to create what social psychologists refer to as a 'hope-cast'. A hope-cast is like a forecast, but where its holder also hopes for the predicted event (Miceli \& Castelfranchi, 2002, 336). Miceli \& Castelfranchi $(2002,343)$ argued subjects attribute moral loading to their hope-casts, espe-

\footnotetext{
${ }^{4}$ There are many notable empirical studies on this topic. However, their application to my core thesis is not easily assessed, as these studies typically don't distinguish between: (a) expectations that are moral demands, (b) expectations that have been created through explicit commitments, (c) the class of expectations that I will in Sect. 5 term 'reasonable', and, (d) other empirical forecasts - such as the predicted distribution of windfall gains. For key studies, teasing out importantly different motives, see: (Dana et al., 2006; Vanberg, 2008; Andrighetto et al., 2015)
} 
cially when there is a human agent responsible for disappointing - 'violating' - those hope-casts. If $\mathrm{X}$ hope-casts that $\mathrm{Y}$ will $\mathrm{A}$ in $\mathrm{S}$, then $\mathrm{X}$ will think $\mathrm{Y}$ ought to $\mathrm{A}$ in $\mathrm{S}$. If his hope-cast is disappointed, the violation will be arousing and upsetting (Burgoon, 1993).

In 2013, Irwin and Simpson investigated the links between descriptive norms, group-membership feelings, and conformity. As predicted, they found strong descriptive norms (with little deviance in performance) increased a sense of felt solidarity and behavioural conformity. Against their initial hypothesis however, this conformity only occurred for some people - the 'pro-socials' who (compared to the less cooperative 'pro-selfs') were more likely to cooperate with others, even at potential personal cost (Irwin \& Simpson, 2013). These pro-socials responded dramatically to strong descriptive norms, contributing more when that was expected, but also lessening their contribution when that was the norm. This article's thesis - that expectations provide morally significant reasons for conformity — would help explain why ethical agents were so responsive to strong descriptive norms.

In 2018, Michael and Székely found developmental evidence linking expectations and obligation. Far from learning about commitment through special norms of promising and agreement, young children begin with a default expectation that, when another person's help is necessary for them to achieve some goal, that person will render the necessary assistance (2018). As they grow, children calibrate this expectation to align with cases where help predictably occurs. (In Sect. 5's terms, I suggest their expectations about help and cooperation become 'reasonable'.)

Finally, Theriault, Young and Barrett (2021) recently developed a novel theory aiming to explain the perplexing normativity of expectations-including why we conform to them, and think we should conform to them. Their theory explaining this 'sense of should' (as they refer to it) suggests that we conform to others' expectations because doing so makes their behaviour more predictable, as they respond predictably to our conformity. By making our social environment more predictable, this lightens our cognitive load (with mental exertion being, like other resource-intensive efforts, something humans are evolutionarily selected to avoid where possible). However, while Theriault and colleagues $(2021,101)$ accept that this 'sense of should' feels like a social obligation, their hypothesis makes it a prudential rule-of-thumb, as the ultimate beneficiary of Y's conformity turns out to be $\mathrm{Y}$ herself. In contrast, I argue that the major stakeholder in Y's conformity is not $\mathrm{Y}$ but $\mathrm{X}$. These high stakes for $\mathrm{X}$ are what drive the felt social obligation - and, I will argue, potentially the normative justifiability—of Y's conformity.

\section{Ethical goods delivered by respecting expectations}

If Y lives up to X's expectations that she will perform action A in situation $S$, then she may contribute to a wide range of ethical goods for X. This section describes these ethical goods. 


\subsection{Loss-avoidance}

Perhaps the most obvious gain from Y's conformity to X's expectations lies in the possibility that $\mathrm{Y}^{\prime}$ 's non-conforming action will cause material losses to $\mathrm{X}$. In taking various actions, perhaps over an extended period, $\mathrm{X}$ may have relied on Y's subsequent action A, such that without her A-ing as predicted, X's goal is not fulfilled. Worse, Y's failure to A might waste much of X's invested resources and efforts.

This concern looms large in explorations of legitimate expectations in law, where years of work and investment can be sundered by capricious legislation (Fuller, 1969). But myriad daily activities (such as Basketball and Waiter) also rely on others behaving as expected (Provis, 2011; Tummolini et al., 2013). Reliance in situations like Inheritance may create much larger risks of material losses. X likely would have managed his finances differently if he had known $\mathrm{Y}$ was not going to follow the descriptive norm.

Expectations can be implicated in material losses in another way. When $\mathrm{X}$ is unable to predict that $\mathrm{Y}$ (and others like $\mathrm{Y}$ ) will A in S, he may eschew opportunities for productive or fulfilling activities (Bentham, 1978/1802). If only he had known that $\mathrm{Y}$ would have been amenable to A'ing in S, perhaps based on her awareness of X's investment in her doing so, then he could have achieved his goals. When Y responds to others' expectations, she contributes to a larger social context facilitating productive action and investment - and the material prosperity and human wellbeing these fuel. For instance, Y's non-conformity to X's expectations in Basketball might waste an hour in disputation. But X's loss of the expectation that Y (and others like Y) will respect the court's conventional arrangements may be more severe. He may forego playing informal basketball altogether, despairing of the continued argument and wasteful conflict.

\subsection{Epistemic gains}

To cope with and flourish in the world, agents must be able to make accurate predictions, especially about their goal-directed activities. This constitutes a critical part of each person's self-efficacy: their confidence in their ability to navigate situations and accomplish tasks (Miceli \& Castelfranchi, 2002; Castelfranchi \& Giardini, 2003).

Often, when Y vindicates X's expectations, she will do so by conforming to various action-scripts, available to both $\mathrm{X}$ and $\mathrm{Y}$. These scripts lay down situation-specific roles, actions, and communications (such as in Waiter (Provis, 2011)). When $\mathrm{Y}$ conforms to these scripts (and there may be various scripts on offer, and choicenodes available within them), this streamlines X's information-gathering, planning, and goal-directed action.

In contrast, when $\mathrm{Y}$ does not conform to $\mathrm{X}$ 's expectations, $\mathrm{X}$ can suffer cognitive distress and disorientation, leading to him feeling uneasy, flustered and anxious (Miceli \& Castelfranchi, 2002; Castelfranchi \& Giardini, 2003, 224; Theriault et al., 2021). Y has stepped off-script, creating more 'moving parts' in X's environment. In high stakes situations, or if multiple off-script actions pile up, $\mathrm{X}$ can feel unprepared and overwhelmed. Unable to gather and process relevant information efficiently, X's cognitions become demanding and difficult, potentially leading to poor practical, 
social, professional, and ethical decisions - or even to an unhealthy desire to avoid such situations.

Alfred North Whitehead $(1911,61)$ famously opined that civilisation advances by extending the number of important operations we can perform without thinking about them. Respect for expectations based on scripts and descriptive norms streamlines people's decision-making, freeing up cognitive resources for other tasks.

\subsection{Autonomy gains}

The predictability of X's world increases the control X has over his life. In a stable environment, choice between alternative long-term options is possible, increasing $\mathrm{X}$ 's ability and confidence to make life plans, and for those decisions to govern his life. This contributes to autonomy and even person-hood itself. Jeremy Bentham $(1978 / 1802,51)$ waxed almost Hegelian in extolling these benefits:

This presentiment, which has so marked an influence upon the fate of man, is called expectation. It is hence that we have the power of forming a general plan of conduct; it is hence that the successive instants which compose the duration of life are not like isolated and independent points, but become continuous parts of the whole. Expectation is a chain which unites our present existence to our future existence, and which passes beyond us to the generation which is to follow.

While Bentham's focus is on legal expectations, social and interpersonal expectations can also contribute to the control people have over their lives. Inheritance provides an example, where Y's failure to conform to X's expectations might greatly impact his life-plans, including his financial arrangements, familial relationships, and social identity. Basketball also empowers autonomy, in this case (inter alia) by clarifying and constraining the types of risks the situation poses. A basketball court operating on informal social norms poses different physical risks as compared with a cafe. By empowering specific activities in specific places, expectations allow people to decide the risks they will bear. To the extent decisions like Y's contribute to self-chosen goal-pursuits in X's life, she assists his capacity to autonomously govern his life.

\subsection{Facilitating virtues and capabilities}

Another benefit of a stable socio-legal environment lies in its gradual impacts upon citizens' character. In cases where the stability of expectations facilitates long-term projects with distant pay-offs (whether social, relational, educational, creative, or commercial), vindicating those expectations facilitates citizens developing virtueslike patience, diligence, and prudence - that achieve those rewards.

As Bentham (1978/1802, 54-56) argued, with no reasonable expectation of reward for problem-solving, hard work, planning and prudence, there is no consistent structure within which these valuable human capabilities may be encouraged, practiced and honed. Instead, disengagement and self-fulfilling pessimism may spread (Miceli \& Castelfranchi, 2002). 


\subsection{Preference-adaptation}

Adaptive preferences occur when people (intentionally or otherwise) adapt their desires to perceived likely outcomes. Adaptive preferences can raise moral concerns, especially when a subject adapts her preferences to an illegitimate or discriminatory polity. However, some adaptation to one's own limitations, and to the possibilities offered by a legitimate polity, is sensible (Elster, 1982; Nussbaum, 2001; Brucker, 2009). Rather than pining for the impossible, as John Stuart Mill (1861/2001, 13) observed, the foundation of a life of happiness is "not to expect more from life than it is capable of bestowing'.

If $\mathrm{X}$ adapts his preferences towards realistic goals, then those adapted preferences will align with his expectations. For example, in Inheritance, X may start planning around his expected inheritance, and in Basketball a local may attach his hopes to success in, and love of, that sport, rather than one that is not locally practiced. As this adaptation occurs, X's preferences about Y's behaviour will shift from an aspiration to something he 'counts on' and has 'got his hopes up' about:

A hope-cast favours a view of the implied goal in terms of maintenance, by inducing an "as if" state of mind: the desired state is viewed as (almost) realized, and the individual feels already allowed to enjoy its satisfaction. (Miceli \& Castelfranchi, 2002, 355)

The normative wording used here-allowed to - is revealing. When people adapt their preferences to the (legitimate) social and legal reality around them, they usually do a very prosocial thing. By scorning wealth, authority, and power that lies beyond their means, they weaken the temptation to achieve such goods in antisocial ways. This helps explain the moralised nature of hope-casts. When we align our desires with reality, we feel like these are desires we are entitled to have - and it can seem like a moral affront for them to be denied. As such, when hope-casts and adapted preferences coalesce, their violation triggers the harsh sting of disappointment, frustration and even anger (Bentham, 1978/1802; Bentham, 2013/1795). Vindicating another's expectations spares them from this emotional tumult, and rewards them for the pro-social act of attaching their desires to realistic outcomes.

\subsection{Conflict-avoidance and pre-emptive non-interference}

Descriptive norms empower activities and interactions to take place without interference, and without requiring protracted negotiation by all stakeholders. Consider Basketball. In well-populated basketball courts with strong descriptive norms, each day does not see decisional priority go to the first group who occupies the court. Nor is there anarchy as multiple actors try to play incompatible games. Nor is there continual re-negotiation with every new arrival. Nor is there deference to some powerful authority. Instead, what happens is basketball. People fall in line with expected behaviour, keeping competition and contestation within settled bounds, ensuring time and energy can be devoted to sport, rather than argument, negotiation, and conflict. Similar cases include norms empowering surfing, skating, billiards and other activi- 
ties occurring on (quasi-)public property, as well as queuing, turn-taking, customary recreation, rights of way, and common-property practices (Cross \& Harris, 1991; Ellickson, 1993; Breakey, 2011).

Conforming to these types of descriptive norms achieves what we might call pre-emptive non-interference. Interfering in people's activities can happen not only through intruding on occurrent activities, but also through preventing people being able to perform those activities in their designated places (Breakey, 2011). If Yvonne is first on the basketball court in the morning, and begins playing futsal, then she impacts on later arrivals' plans as much as if they arrived first, and she began playing futsal during their basketball game.

This empowerment of specific activities (or several compatible activities, or turntaking) can extend the diversity of available options. Even a single beach may have dedicated areas for different activities, created by no more than mutually shared informal expectations and new arrivals' willingness to fall in line.

Ultimately, because of the material, epistemic and preference-adaptation stakes involved in expectations, conflict will often follow from unconformity, whether it is a manager having to demand a customer leave (in Waiter), angry accusations in the wake of a betrayed confidence (in Secrecy), or a devastating family rupture (in Inheritance).

\subsection{Social recognition and cohesion}

Conforming to others' expectations, when these are set by a descriptive norm, signals respect for local conventions and practices. Y's conformity to contingent, historically-constructed practices requires personal sensitivity to local ways, and can be recognised as such. While 'leaving others alone' may be a crucial moral guard against harm and interference (Mill, 1861/2001, 60), as a way of morally respecting others, it can appear indistinguishable from ignoring, dismissing, or even scorning them. In contrast, when one conforms to expectations, one's action usually displays sensitivity to others' actions and goals.

While allowances may be made for newcomers and outsiders, those conforming to shared expectations mark themselves as knowledgeable about — and sometimes experts in - local ways. In so acting, Y can be recognised as 'one of us' - a member in good standing of a shared moral community. And Y can recognise herself similarly, enhancing her sense of social identity, as each 'confirms one another' as proper community-members (Irwin \& Simpson, 2013). Unsurprisingly, empirical studies suggest mutually inter-locking expectations and behaviours lead to greater social cohesion (Theriault et al., 2021, 118).

This leads naturally to the links between expectation and etiquette-perhaps the only other domain where one finds moral recommendations for 'reliable conformity' and 'deference to social environments' (Olberding, 2016, 431-443). Expectations and etiquette_-including social rites and rituals_-possess many similarities. Both give moral significance to historically and culturally constructed practices; both avoid conflict by lending order to everyday interactions; both can communicate mutual respect and social belonging, and both make social existence more easy, pleasing, and manageable (Provis, 2015; Olberding, 2016). True, there remain impor- 
tant differences - habitual conformity to expectations may suffice, but for etiquette, programmatic adherence is less acceptable (Olberding, 2016, 434). However, the valuable goods delivered by etiquette - conferring respect, recognition, and social grace - can be achieved by conformity to expectations. Waiter provides an example where the shared expectations of experienced diners and expert staff can create a polished atmosphere of seamless grace. In Secrecy and Inheritance, each person's reliance on the other did not need to be spelled out, allowing the intimate relation, rather than explicit contract, to ensure trust.

\subsection{Conveying trustworthiness and nurturing relationships}

When Y conforms to X's expectation-such as in Basketball or Secrecy-she communicates that she is a good co-operator: someone $\mathrm{X}$ and others can rely on as a partner in joint actions, including social or commercial endeavours (Dana et al., 2006; Heintz, Celse et al., 2015). This is sometimes a self-interested motive, but if Y's conformity to expectations is part of a genuine, consistent disposition, then her communication to $\mathrm{X}$ and others that she is a trustworthy co-operator possesses moral significance.

A similar prudential-cum-ethical motive arises with respect to the maintenance of important relationships. There can be a self-interested motive to be included in profitable partnerships and effective teams (Michael \& Székely, 2018). But equally, living up to relationship expectations can carry moral weight as one confirms one's care and consideration to colleagues, family, and friends.

There also can be cases where conforming to role-expectations helps agents from stumbling into wrongdoing, such as abuses of power or conflicts of interest. For example, following teacher-student or therapist-patient scripts helps keep expectations clear and appropriate.

In such cases, the combined prudential and ethical benefits from conforming to others' reasonable expectations can be found in sayings like, 'When in Rome, do as Romans do,' and, 'Go along to get along'. While both are good practical advice, the personal benefits of the recommended conformity arise from the social impact on others, and from their subsequent recognition that the actor is someone it is valuable to have around.

\subsection{Summation}

There are many ways Y conforming to X's expectations can contribute to substantial ethical goods for X. But does this just apply to certain types of expectations? It is to this question we now turn. 


\section{Reasonable expectations}

This section describes a class of 'reasonable expectations' $\left(\right.$ expectations $\left.^{R}\right)$, delineated by five criteria, that reliably trigger Sect. 4 's ethical goods. ${ }^{5}$

\subsection{Epistemic rationality}

$\mathrm{X}$ 's expectation must be epistemically rational. In predicting that $\mathrm{Y}$ will perform action $\mathrm{A}$ in situation S, X must have solid evidence for his belief. Because irrational predictions are not based upon either descriptive norms or past behaviour, conformity will not empower joint activities and allow pre-emptive non-interference. Furthermore, desires based on flawed predictions are not reflective of people sensibly adapting their preferences to reality, but rather hoping reality will adapt to their preferences. Indeed, if $\mathrm{Y}$ was morally obliged to conform to others' unrealistic predictions, the resulting unpredictability would hamper her ability to rationally adapt her preferences and govern her life.

\section{2 'Active' hope-casts}

Y performing A must be not only predicted but also valued by $\mathrm{X}^{6}{ }^{6}$ That is, $\mathrm{X}$ hopecasts that Y will A in S. Indeed, in order to capture Sect. 4's ethical goods we must require $\mathrm{X}$ 's prediction is what we might call an active hope-cast. In an active hopecast, X's hope-cast that $\mathrm{Y}$ will $\mathrm{A}$ in $\mathrm{S}$ has impacted upon X's working, planning, investing, or acting. Rather than $\mathrm{X}$ merely holding an idle wish that $\mathrm{Y}$ will A, unconnected to his intentional pursuits, Y's A-ing contributes to a goal that X actively pursues, and he has relied upon her A-ing (Castelfranchi, 2005; Michael \& Székely, 2018). This is because expectations that $\mathrm{X}$ relies and depends on in the pursuit of his desires and goals are the only ones whose violations trigger X's investment and labour costs, autonomy losses, and self-efficacy threats, and involve $\mathrm{Y}$ interfering in $\mathrm{X}$ 's activities and practices.

\subsection{Moral tolerability}

The expected action A must be 'morally tolerable'. I use this term to refer to three conditions. First, A is a fixed action, or at least is not linked to arbitrary command. For example, Action A cannot be: 'Do whatever the boss-man commands'. Second,

\footnotetext{
${ }^{5}$ These criteria are not necessary and sufficient conditions for imposing an obligation. Section 7 shows why they are not sufficient: countervailing moral considerations may mean imposing an obligation would be inappropriate. Conversely, the criteria may not be all jointly necessary: there may be times when ethical goods apply strongly to expectations that do not fulfil all five criteria. For example, there may be cases where $\mathrm{Y}$ knows that $\mathrm{X}$ is critically depending on $\mathrm{Y}$ performing $\mathrm{A}$ in $\mathrm{S}$ - and where his expectation is epistemically unreasonable, but nevertheless understandable. Or a case where X knows Y should be aware of his dependence on her A-ing in S, but also knows she is not so aware.

${ }^{6}$ I focus on cases where X's desire, and ensuing reliance, attach straightforwardly to Y's performance of $\mathrm{A}$ in $\mathrm{S}$. Ethical obligation is murkier in more conflicted cases, such as when $\mathrm{X}$ dislikes $\mathrm{Y}$ 's performance of A (considered in isolation), but nevertheless relies on his expectation of it to secure some larger goal.
} 
performing $\mathrm{A}$ in $\mathrm{S}$ does not require $\mathrm{Y}$ violate basic moral duties, or support $\mathrm{X}$ in his doing so. By 'basic moral duties' I refer to commonplace obligations of non-harm, honesty and non-cheating shared across many cultures and mainstream ethical theories, notwithstanding their other differences (see Breakey, 2018, 533-538). Thus, A cannot involve lying, stealing or physically harming others. Third, the imposition on $\mathrm{Y}$ to $\mathrm{A}$ in $\mathrm{S}$ might respond to somewhat arbitrary distinctions. For example, as a youth, Y might be socially expected to give up her seat on the bus to her elders (even if the youth is tired and the elder is spry). However, the imposition cannot be harmfully discriminatory in the sense of communicating that members of one group are intrinsically inferior to another group, that they are less trustworthy, should be more subservient, or any other generalised claim undermining their equal worth and autonomy. For example, as a person of a specific ethnicity, Y cannot be expected to give up her bus-seat for a privileged person.

This three-part property of moral tolerability by no means exhausts the ethical concerns that can arise with expectations (as we will see in Sect. 7). However, it sets a critical moral minimum that expectations must meet if they are to become obligations, as the nature of morally intolerable expectations strips them of moral significance.

First, if arbitrary command was allowed, then conforming to expectations would make it impossible for Y to achieve the ethical goods of epistemic ease, virtue-facilitation, wise-decision-making, and self-governance, as she could not plan around, and build her character around, stable and predictable duties.

Second, if intrinsic wrongs violating basic moral duties of honesty and non-maleficence were allowed, then conformity would no longer mark social cooperativeness. Indeed, Y's conformity to morally wrong practices would mark her as untrustworthy, because others (even including $\mathrm{X}$ ) could never be sure she wasn't going to lie or harm to fulfil others' expectations. Moreover, in cases where stakeholders routinely resist, thwart, and morally contest practices (as would be typical when those practices involve lying, cheating, and harming), there is no seamless interlocking of mutual expectations, and so no benefits from conflict-avoidance and pre-emptive non-interference.

Third, conforming to expectations based on discriminatory descriptive norms would communicate the opposite of social recognition, respect, and inclusiveness. In the next section we will discuss how conforming to expectations can be justified by considerations of reciprocity and fairness. But these cannot attach to discriminatory descriptive norms. As an 'inferior', 'less trustworthy' or 'rightly subservient' community-member, Y would consistently bear greater obligations, and not share equitably in created goods.

\subsection{Known and/or knowable}

As a general rule, in order to be bound by an obligation to S, Y must know, or at least be in a position where she can be assumed to know, (a) that others hope-cast that she performs A in S, (b) that such hope-casts are epistemically reasonable, and (c) that such hope-casts are being relied upon. That is, $\mathrm{Y}$ is understood to be aware of con- 
ditions 1 and 2 above. ${ }^{7}$ This knowledge/knowability requirement follows from the general ethical requirement that 'ought requires can'. That is, in order to conform to a duty, one must be able to conform to that duty, which requires being knowing about, or being able to know about, the duty.

Note though that this requirement only requires the obligation being knowable at the point where the obligation must be performed, and not necessarily at the point where the obligation is triggered. We saw earlier (in Sect. 2) in cases like Secrecy and Waiter that a subject might acquire an obligation at one point (being told a secret/ giving one's food order), and then be informed of their obligations later (but before they have violated those obligations).

That said, it is clearly morally preferable for $\mathrm{Y}$ to be able to know what obligations she will acquire before those obligations are triggered. This better respects her autonomy, as described in Sect. 4.3 above, by allowing her to control the obligations under which she will be bound.

In terms of knowledge, for complex descriptive norms, it may be enough that $\mathrm{Y}$ tries her best to conform, given her limited knowledge. For example, in stepping onto the busy basketball court, Y might not know the local practices about how teams are formed, how turn-taking works, and so on. It is normally sufficient that she tries to learn and fall in line with these practices, rather than being required to immediately know them all. (However, this may not hold true for cases where harm is risked if the descriptive norms are not followed, such as practices of wave selection in surfing.)

As a final point, these knowledge requirements might mean that some arrangements are unlikely to create obligations. For example, cases where $\mathrm{X}$ knows about Y's practices only from the testimony of a third party Z (rather than from X's personal experience or a descriptive norm) might fail to create an obligation, because X's epistemic surety about Y's practices, and Y's epistemic surety about X's beliefs and values might not meet the standards laid down in criteria 1 and 4 above. ${ }^{8}$

\subsection{No neutralising expectations}

In some cases, a well-established over-arching expectation might dictate that Y's decision to $\mathrm{A}$ in $\mathrm{S}$ should be made in isolation from any concern with others' hopecasts. Others' low-level hope-casts in such a case are neutralised as a source of moral consideration by this over-arching 'neutralising expectation'. Consider Waiter. On basis of the ethical goods surveyed in Sect. 4 above, the waiter's hope-cast that Y considers her order in a timely way possesses moral significance (see Provis, 2011, 54-60). However, we can imagine a situation where the waiter also hope-casts, based on previous patrons' behaviour, that $Y$ will choose one particular menu-item, and that $\mathrm{Y}$ knows this. In this case, I submit, Y's choice is protected by a well-established over-arching expectation that restaurant patrons are entitled to consider only their own personal preferences in making their choice. Y's selection is quarantined from factoring in X's hope-cast, and his expectation holds no moral weight. Similarly, in

\footnotetext{
${ }^{7}$ There are complexities here. $\mathrm{Y}$ can only operate off what she knows. If $\mathrm{Y}$ believes that $\mathrm{X}$ expects ${ }^{\mathrm{R}}$ her to $\mathrm{A}$ in $\mathrm{S}$, then she will be under an obligation to do so (notwithstanding that $\mathrm{X}$ may have changed his plans).

${ }^{8}$ Note also the factor discussed in Sect. 8.2 below.
} 
Basketball, there is an established overarching expectation that Yvonne is entitled to pursue her team's victory on the courts, even if spectators strongly hope-cast that the local champ's team will prevail. (Neutralising expectations are common in competitive contexts: see (Kershnar, 2014).)

In cases where there is a well-established, overarching expectation allowing Y's behaviour to follow her subjective preferences, the moral reasons for conforming to expectations ${ }^{\mathrm{R}}$ apply to that expectation, and not lower-level hope-casts. As the above examples suggest, neutralizing expectations often have an important function. The point of basketball games and cafes would be undermined if attempts at winning and culinary preferences could be trumped by local hope-casts.

\subsection{Summation}

As I have described the class of reasonable expectations, $\mathrm{X}$ expects ${ }^{\mathrm{R}} \mathrm{Y}$ to $\mathrm{A}$ in $\mathrm{S}$ when he hopes, predicts, and acts in reliance of Y A-ing in S. In addition, A must not be manifestly immoral or discriminatory, or protected by an over-arching expectation that A-ing be subject only to Y's personal choice. Finally, Y must be aware that others (like $\mathrm{X}$ ) hope-cast that she $\mathrm{A}$ in $\mathrm{S}$, and that they rely on, and have good epistemic reasons to hold, that expectation.

\section{From goods to duties}

In this section, I argue that in cases where $\mathrm{X}$ expects $^{\mathrm{R}}$ (as defined in Sect. 5) $\mathrm{Y}$ to $\mathrm{A}$ in $\mathrm{S}$, that we have good reasons to acknowledge $\mathrm{Y}$ has a defeasible moral duty to $\mathrm{A}$ in $\mathrm{S}$. To begin, I describe some morally relevant information conveyed by descriptive norms. I then enumerate several general ethical reasons for recognizing prima facie obligations to respect expectations ${ }^{\mathrm{R}}$. For those readers with specific moral theoretic commitments, I argue (in the remaining subsections) there is a plausible path to $\mathrm{Y}$ holding a moral obligation based on the four main ethical perspectives: utilitarianism, deontology, virtue theory and communitarianism. ${ }^{9}$ Of course, given the diversity of ethical theories within these approaches, these explorations remain only preliminary.

Before beginning, two considerations.

First, to say that $\mathrm{Y}$ is under an obligation to conform to X's expectations does not mean $\mathrm{Y}$ cannot work to alter, reform, or revise the basis for that expectation. For example, suppose Y has a moral obligation to conform to expectations in Inheritance. Even so, Y might elsewhere try to persuade others to alter those norms, such that all children inherit equal shares of their parents' wealth.

Second, recall that I aim to show that $\mathrm{Y}$ can have a prima facie obligation even when: Y has not intentionally created X's expectations; where $\mathrm{Y}$ and $\mathrm{X}$ do not explicitly share a joint goal requiring a coordinating convention; and where $\mathrm{Y}$ has not

\footnotetext{
${ }^{9}$ While I will speak of an 'obligation', each ethical theory will characterise Y's moral requirement in different ways: for deontological theories, it will be a (usually directed) duty; for utilitarianism, an optimific rule-of-thumb; for virtue ethics, a principle of action exemplifying valuable character traits; and for communitarianism, playing one's role in a valuable social practice.
} 
directly partaken of the benefits of X A-ing. But often these three factors will be present. Where they are, it seems plausible to think $\mathrm{Y}$ will have additional reason to be morally obliged to A. For example, in cases where Y intentionally creates X's expectation, this increases $\mathrm{Y}$ 's responsibility for X's reliance, even as it reduces the ensuing obligation's potential burden for Y, and the potential impact on Y's autonomy (as, if it does not suit $\mathrm{Y}$, she can simply avoid intentionally creating the expectation (Scanlon, 1990; Scanlon, 1998)). Thus, intentional expectations creation would provide additional reason for holding $\mathrm{Y}$ to be obliged to $\mathrm{A}$ in $\mathrm{S}$. In cases of direct promise, the obligation would be more strongly justified again (this aligns with Vanberg's (2008) empirical research, showing explicit promises have a strong, independent impact on behaviour).

\subsection{Morally relevant information conveyed by the descriptive norm}

Consider those cases where X's expectation ${ }^{\mathrm{R}}$ about Y A-ing in $\mathrm{S}$ is based on a descriptive norm, intersubjectively known to both $\mathrm{X}$ and $\mathrm{Y}$, that similarly-placed others historically $\mathrm{A}$ in $\mathrm{S}$. The mere fact that $\mathrm{A}$ is a descriptive norm may convey information that, from Y's perspective, is morally informative.

First, the fact of the descriptive norm may helpfully communicate the expectations. Y can understand what is expected by observing what actions are performed in $\mathrm{S}$, and whether they are they met with approval.

Second, the existence of the descriptive norm shows that A-ing in $\mathrm{S}$ is feasible and achievable. Y is not being asked to do something extraordinarily difficult or that violates other commonplace obligations - as evidenced by the fact that so many others perform A. Indeed, Y might find alongside the expectation that she A in S is a corollary expectation that others support and facilitate her A-ing. The existence of a longstanding norm might also imply that the practice is sustainable and effective - that it succeeds in achieving the goals of those who participate in it, like playing basketball, or ordering food. (A stronger claim posits that a longstanding practice, in surviving a type of natural selection, is likely to be adaptive (Harpine, 1993)).

Third, the descriptive norm (which as an expectation ${ }^{R}$ is not discriminatory or linked to arbitrary authority) provides reason for Y to think that the obligation has not been arbitrarily imposed, and that there is at least a thin type of procedural fairness at work. That is, Y is being asked to do the same thing all similarly-placed others are asked to do. She is not being singled out.

None of these considerations guarantee $\mathrm{Y}$ has a duty to $\mathrm{A}$ in $\mathrm{S}$. However, they are reasons to think A might be a candidate for a duty. If the moral obligation was unclear, unfeasible, or pointless, or it arbitrarily singled out $\mathrm{Y}$, these would be good reasons to think it couldn't be a moral obligation.

\subsection{General ethical reasons for acknowledging a prima facie moral obligation to conform to expectations}

From a practical ethical perspective, a moral agent, realising that another person expects ${ }^{\mathrm{R}}$ them to do something, should perceive that this will implicate issues of lossavoidance, autonomy, conflict-avoidance, preference-adaptation, and risk-minimisa- 
tion. There will also be, as I describe below, matters of consent, fairness, and mutual respect in play. In addition, the constitutive properties of expectations ${ }^{\mathrm{R}}$, especially the moral tolerability conditions, provide constraints on how obligations based on those expectations can arise, and ensure the duties are imposed without discrimination. Absent countervailing moral considerations, I submit an ethical agent should therefore recognise they are prima facie obliged to conform to that expectation ${ }^{R}$.

Thus, when $\mathrm{Y}$ in $\mathrm{S}$ knows $\mathrm{X}$ expects ${ }^{\mathrm{R}} \mathrm{Y}$ to $\mathrm{A}, \mathrm{Y}$ thereby acquires what David Ross $(2002 / 1930,21)$ would term a 'prima facie duty'. That is, Y's performance of A tends to be a duty, and will be a duty unless A in a given situation involves breaching another duty. (Expectations ${ }^{\mathrm{R}}$ can breach other duties, as we will see in Sect. 7 below.)

Ross $(2002 / 1930,27)$ approaches this thesis himself, holding that a prima facie obligation arises where 'we intentionally create an expectation that we can be counted on to behave in a certain way in the interest of another person'. Because Ross considers only intentionally created expectations, understanding them as implicit promises, he invokes a prima facie duty of fidelity. However, this paper's arguments show that in different contexts, conforming to expectations ${ }^{\mathrm{R}}$ can also be (in Ross' typology) prima facie duties of justice, beneficence, non-maleficence, or gratitude.

However, prima facie obligations need not be formed only through the confines of Ross's specific theory. I outline below how expectations ${ }^{\mathrm{R}}$ generate duties for mainstream ethical approaches like utilitarianism and deontology. From the perspective of an everyday ethics not wedded to any specific theoretical approach, each of these approaches can be thought of as capturing a plausible insight about ethical life (Sampford, 1994). As such, an ethical agent can acknowledge a prima facie duty to conform to an expectation ${ }^{\mathrm{R}}$ on the grounds that it is fair, improves human wellbeing, respects consent, encourages virtue, and pays heed to locally constructed ethical cultures.

\subsection{Utilitarianism}

The utilitarian case for respecting expectations ${ }^{\mathrm{R}}$ is straightforward. We noted earlier that expectations ${ }^{\mathrm{R}}$ often overlap with adapted preferences, meaning that they have been aligned with what is likely, and that the preference for them has been strengthened. These are both reasons for utilitarians to take expectations ${ }^{\mathrm{R}}$ seriously (Mill, 1861/2001, 13; Bentham, 1978/1802, 49; Bentham, 2013/1795, 292). Utilitarians concerned either with preference-satisfaction or felt-happiness have reason to fulfil strong preferences whose frustration triggers emotional tumult. As well, utilitarians will want to promote preference adaptation to legitimate regimes. The more people desire things they have good reason to believe will be realised, and refrain from fanciful ambitions, the greater the overall subjective happiness and preference-satisfaction. Indeed, preference adaptation in line with expectations ${ }^{\mathrm{R}}$ furthers the development of compossible preferences across a population - a particularly desirable outcome from a utilitarian perspective. Similarly, vindicating people's predictions avoids epistemic anxieties, encourages cognitive confidence, and promotes productive, prudential capabilities - all of which contribute to human wellbeing. So too, conforming to expectations ${ }^{\mathrm{R}}$ about descriptive norms will discourage conflict and allow seamless collective action. As such, a utilitarian agent $\mathrm{Y}$ will have good reason to think - as a reliable rule of thumb - that conforming to X's expectations ${ }^{\mathrm{R}}$ will 
deliver significant ethical goods. These goods might be directly achieved: avoiding X's immediate loss, frustration, and disappointment. Or they may be indirectly facilitated: encouraging rational preference-adaptation, and the prosperity resulting from constructive cooperation.

\subsection{Deontology}

Conforming to reasonable expectations aligns with hallmark concerns of deontological ethics, including non-interference, consent, and fairness. We have already seen how conforming to active expectations ${ }^{\mathrm{R}}$ about descriptive norms (such as in Basketball) achieves pre-emptive non-interference.

Conforming to others' expectations ${ }^{\mathrm{R}}$ can also respect their consent. Consent entangles with expectation in complex ways. Entering onto others' property, whether personal or commercial (such as Waiter), usually requires behaving in ways that implicitly follow the reasonable expectations of the property-owner or her delegates (Provis, 2011). The same holds for consent to interpersonal interactions. In Secrecy, Xavier's interaction with Yvonne is based upon his trust in Yvonne. If she later reveals the secret, she treats him in a manner to which he did not consent. Even an ongoing relationship - such as Xavier's regular interactions with his sister in Inheritance - may be premised on his expectations about the inheritance. In addition, as we saw earlier, expectations inform people's consent to exposure to risk. In entering a restaurant, Yvonne accepts a different level of risk to stepping onto a basketball court. It would be a serious wrong to expose her to the dangers of the latter in the context of the former. In these ways, expectations help delineate the terms of implicit and explicit consent, and form a status quo basis for future consent to modify.

Reciprocity and fairness also can be at work in expectations ${ }^{\mathrm{R}}$. While (as aforenoted) we are exploring cases where $\mathrm{Y}$ has not previously benefited from others' A-ing in $\mathrm{S}$, if we take a wider viewpoint, $\mathrm{Y}$ will likely have routinely benefited from others living up to her expectations ${ }^{\mathrm{R}}$ in other contexts. While the various benefits derived from different contexts may not be entirely equitable, it may nevertheless be fair for $\mathrm{Y}$ to shoulder obligations when it is her turn (for an analogous argument applied to law, see Gur, 2013). It is a case of 'swings and roundabouts'. Yvonne might be inconvenienced by expectations ${ }^{\mathrm{R}}$ about basketball, but gain from expectations ${ }^{\mathrm{R}}$ about (say) privacy and inheritance.

These issues of fairness, non-interference, consent and property-rights all link to well-known deontological concerns. ${ }^{10}$ Many tie to the Kantian principle of humanity, and its requirement (as a perfect duty) to not treat others in way to which they would not or could not consent (Kant, 1785/2008; Formosa, 2017).

But can expectations create a perfect, directed duty - that is, a duty that must be performed in a particular context and that is owed to another specific person? Intuitively, it might be thought a deontological regime would insist that only consent (or, at most, implied consent) could create such duties. However, a clue the obligation might be perfect and directed is that targeted resentment characteristically follows a

\footnotetext{
${ }^{10}$ Other scholars have linked respect for expectations to a deontological principle of beneficence: (Provis, 2011, 59-60; Michael \& Székely, 2018, 116).
} 
person breaching expectations ${ }^{\mathrm{R}}$. In all four illustrative cases, it is intuitive to think (and the social psychology suggests, Castelfranchi, 2005, 224-225) that X would resent $\mathrm{Y}$ for letting him down. More substantively, the above-noted considerations implicate moral rights, such as of rights of privacy (Secrecy), of non-interference (Basketball), and to recompense for services rendered (Waiter). If moral rights are indeed in play, then directed obligations will plausibly follow from them - to violate a right is to fail to grant another what is owed to them. Finally, upon close examination, deontological systems commonly allow the non-consensual triggering of perfect and directed duties. For example, taking possession of an object, utilising public spaces, and occupying a space for purposes of shelter all create (or activate) new perfect, directed duties for others (van der Vossen, 2015, 68-72). If I pick up a stick out in the woods, then (ceteris paribus) everyone in the world non-consensually acquires a perfect duty, owed to me, not to grab the stick from my hand. As such, there is no reason to rule out the possibility of directed, perfect duties arising from expectations ${ }^{\mathrm{R}}$, especially when moral rights are in play.

Finally, deontological duties to respect expectations ${ }^{\mathrm{R}}$ could also be grounded in Scanlon's (1998) contractualism, where an act is wrong if and only if it could not be justified to others on grounds that they could not reasonably reject. Scanlon's contractualism already led him $(1998,339)$ to set down his 'Principle of established practices', which provides a narrow 'tie-breaker' justification for respecting conventional arrangements. (Roughly: if there are two non-rejectable but incompatible principles that could govern an activity, and one is an established practice, then it is wrong to violate that practice.) If the foregoing arguments are correct, then they would deliver weighty reasons-highlighting the burdens and problems created by shattered expectations $\mathrm{s}^{\mathrm{R}}$ - for contractualist moral agents to respect social norms and reasonable expectations. In fact, a brief version of exactly this argument has recently been made, with Aaron Salomon (2021, 7) arguing (in line with Sect. 4.2 and 4.3's arguments) on the basis of people's needs to plan and execute projects, for a much stronger contractualist respect for established practices.

\subsection{Virtue}

There are two virtue-based strands of argument for living up to others' expectations ${ }^{\mathrm{R}}$. The first concerns Y's pursuit of, and display of, her own virtue. On this footing it can be peaceable and beneficent (for reasons noted above under utilitarianism) or honest, fair, and just (for reasons noted above under deontology) to conform to others' expectations ${ }^{\mathrm{R}}$. It might also be prudent, by enabling future co-operative-ness. Above all, the action is sociable. It demonstrates one's fitness for life in society and its mutual, interlocking expectations. All these traits (beneficence, honesty, prudence and sociability) have been historically understood as virtues (MacIntyre, 1981). From the Eastern tradition, we might further note the virtue of reliability (Provis, 2015).

The second strand focuses on the positive impact one can make on others' character (presuming it is virtuous to develop virtue in others). As we saw in Sect. 4, conforming to others' expectations ${ }^{\mathrm{R}}$ encourages their autonomy and long-term decision-making, rewarding their personal prudence. So too, it nurtures the emotional and 
cognitive dispositions that flourish in stable social-economic superstructures, such as initiative, patience, and industry.

\subsection{Communitarianism}

Respect for expectations ${ }^{\mathrm{R}}$ based on descriptive norms fits naturally into communitarian ethics, with its focus on the thick ethics of socially constructed practices, rather than the thin morality of universal rules. Conforming to descriptive norms contributes substantially to people's social identity - encouraging their felt-solidarity with similarly behaving others (Irwin \& Simpson, 2013). Adhering to expectations ${ }^{\mathrm{R}}$ also displays social recognition to locals in a way that respects their practices. Such adherence also encourages cultural diversity; it gives an idiosyncratic cast to obligations, allowing them to respond to local activities and values. In this way, expectations ${ }^{\mathrm{R}}$ lend weight to customs and traditions, granting ethical force to longstanding practices.

These features can be expressed through Alasdair MacIntyre's communitarianism. MacIntyre's practices are socially-established cooperative activities that deliver internal goods and excellences (MacIntyre, 1981, 175). These practices create and incorporate descriptive norms. Conformity to expectations about these norms will be motivated by each members' pursuit of the practice's internal goods and excellences. In this way, a socially constructed practice of respecting expectations ${ }^{\mathrm{R}}$ based on descriptive norms can be fuelled by local community-members' rich ethical traditions.

\subsection{Summation}

This section has argued that, on the basis of both common-sense ethics and scholarly theory, we have reason to acknowledge a prima facie obligation to respect expectations ${ }^{\mathrm{R}}$.

\section{Ethical problems with respecting reasonable expectations}

Expectations - even expectations ${ }^{\mathrm{R}}$ - are not an unqualified good. This section notes three serious issues that may prevent them forming ultima facie obligations.

\subsection{The stifling straitjacket of social expectations}

Many readers will have felt the crushing pressure of social expectations, demanding a conformity restricting them from following the road less travelled, experimenting in different ways of living, speaking authentically, or acting spontaneously. Of course, many stifling social expectations will not be expectations ${ }^{\mathrm{R}}$ - for example, they might be passive rather than active expectations. But even expectations ${ }^{\mathrm{R}}$ can be a problem. They create stability and predictability by requiring conformity, and this may come at the expense of innovation, experimentation and diversity (Mill, 1859/2003, 55). This will be especially so if the duties are pervasive or burdensome. 
That said, descriptive norms and expectations ${ }^{\mathrm{R}}$ can promote diversity and spontaneity. Having different descriptive norms in different situations allows diverse practices to be nurtured. A world without contingent, socially constructed descriptive norms would possess greater cultural sameness. Equally, expectations can encourage spontaneity and experimentation, with times set aside for bohemian creativity, spontaneous individuality, and risk-taking.

Yet it remains true that the social and moral power of expectations ${ }^{\mathrm{R}}$ can create a worrying 'subjection to stability'-Rousseau, for example, struggled with social expectation's darker sides (Seigel, 2005, 218-220). At some point, the cumulative ubiquity and demandingness of expectations ${ }^{\mathrm{R}}$ impact upon individuality and spontaneity, at real cost to human freedom and wellbeing.

\subsection{Inequity and the privileging of past power}

Expectations - both reasonable and unreasonable — are historically created. They are inevitably conservative, privileging the old and the established over the new and innovative.

This privileging can be arbitrary. Y may be obliged to perform A in S simply because (through entirely contingent events) A tended to occur in S. However, the privileging may reflect past inequities. For example, in Basketball, expectations ${ }^{\mathrm{R}}$ favoured the use of public spaces for that sport. Historically, the social expectations determining how the courts were used may have prohibited women from access. In the process of reform from unreasonable to reasonable expectations, let us assume, this explicit sexism has been removed. Yet the present expectations ${ }^{\mathrm{R}}$ treating women like men still may be inequitable. If the descriptive norms are strictly meritocratic, they may grant men better access to the courts simply through their greater average height. Alternatively, basketball might be more socially supported for men. In either case, the expectations ${ }^{\mathrm{R}}$ will privilege men's physical activities. This inequity (if accompanying similar inequities elsewhere) can undermine the moral force of expectations ${ }^{\mathrm{R}}$.

\subsection{The difficulty of reform}

People's reliance on expectations ${ }^{\mathrm{R}}$ can create a strong ethical-cum-social force resisting modification or dissolution, even in situations where descriptive norms are creating problematic results (similar concerns are raised in a legal context in Waldron, 1998).

Sometimes expectations can be easily shifted. A norm of men opening the door for women can rapidly evolve into a generalised etiquette. Alternatively, legal change might shift behaviour, giving rise to new descriptive norms or neutralising expectations.

Yet sometimes the inter-linked system of expectations may prove resistant to reform because everyone relies on it, and any single attempt to create a 'new normal' is met with hostile pushback. Section 6's introduction described a version of Inheritance where $\mathrm{Y}$ conformed to the descriptive norm even as she lobbied for change. It is possible to imagine that $\mathrm{Y}$, Y's partner, and $\mathrm{X}$ would all prefer a non-gendered 
inheritance practice, even as they all agree $\mathrm{Y}$ should nevertheless conform to the expectation. Sometimes however, the moral need to reform the descriptive norm will be strong enough to justify noncompliance. Indeed, noncompliance might be the very tool of nonviolent resistance $\mathrm{Y}$ uses to push for change.

A further worry is that the attempt to change a descriptive norm may not result in morally improved expectations ${ }^{\mathrm{R}}$, but instead the wholesale collapse of expectations ${ }^{\mathrm{R}}$ in that context, undermining epistemic, adaptive, social-recognition and autonomyrelated goods.

Ultimately, expectations ${ }^{\mathrm{R}}$ may prove brittle and unyielding, even in the face of widespread dissatisfaction. The uncomfortable truth is that sometimes expectations ${ }^{\mathrm{R}}$ will have both positive and negative moral qualities, implicating important ethical goods even as they entrench inequity and chill diversity. In making a moral decision about how to proceed - individually or collectively — we must be cognisant of both sides of the moral ledger, and consider whether there are processes or compromises that might salvage the full array of available moral goods.

\section{Further considerations}

This section explores two further areas warranting reflection.

\subsection{Promoting respect for unreasonable expectations}

Conforming to expectations ${ }^{\mathrm{R}}$ can set the stage for conforming to unreasonable expectations, making good-hearted moral agents vulnerable to manipulation. The advice, 'When in Rome, do as Romans do,' often applies to contexts where the hearer has limited personal experience. Usually, it is sound. If newcomer Y adheres to Roman descriptive norms when in Rome, she will respond appropriately to many new situations. She may understand she is expected to $\mathrm{A}$ in $\mathrm{S}$ long before she gleans the point of A-ing in S, and what larger goals this practice empowers, or what disputations it prevents. Obeying expectations allows $\mathrm{Y}$ to function — socially, pragmatically, and morally - in an environment where she has not yet learned the 'sense' behind the norms. But Y's default stance to conform might lead her into treacherous terrain.

Consider the shocking results of the (in)famous Milgram experiments. While there were many factors impacting the subjects' stunning willingness to inflict pain, the above arguments lend weight to Milgram's conjecture about the role of 'ambiguity of expectations' (Milgram, 1963, 377-378). The experiment's subjects were clerks, salesmen and laborers. Isolated and thrust into an unfamiliar situation, it would have been natural for them to take behavioural cues from the only person familiar with the new context - the mild-mannered scientist politely instructing them to continue. Indeed, the experiment's ingenious setup, where the subjects did not even think they were the subjects, hammered home these expectations, with the scientists telling wavering subjects that, 'The experiment requires that you continue' (Milgram, 1963, 364). Given this setup, an ordinary citizen, attuned through long experience to (what I have argued are) the everyday moral goods of "going along to get along", could have been led into serious wrongdoing. 


\subsection{Personal behaviour and the ease of dissolution}

Throughout, I have focused on descriptive norms known intersubjectively to all parties. Often in these cases (e.g. Basketball and Inheritance) the duty-bearer cannot 'get in first' and assert before reliance occurs that they are not going to conform. But in other cases it may be possible for X to flag that she does not intend to A, and thereby remove the reliance and the ensuing duty.

This point holds special significance for expectations based on personal behaviour. Such expectations ${ }^{\mathrm{R}}$ can only give rise to duties when it is easy to effectively communicate one's deviance from normal practice to those relying on it. For example, suppose $\mathrm{X}$ sets his watch each day as the ever-reliable $\mathrm{Y}$ passes his front gate on her afternoon constitutional. Even if Y knows people rely on her, it would be inappropriate to impose a duty to continue her practice, for $Y$ has no easy way of communicating any planned deviations to her routine. This provides a further defeating condition between expectations ${ }^{\mathrm{R}}$ and moral obligation.

\section{Conclusion}

New students of philosophy are often surprised - and perhaps disappointed - to discover that the roots of the words 'ethics' and 'moral' refer to custom, practice, or habit. Even our modern word 'norm' possesses a prescriptive meaning ('principle of right action') and a descriptive meaning ('average, median, typical'). If the foregoing arguments are correct, then these longstanding ambiguities house a kernel of wisdom. Sometimes, normal is normative.

Acknowledgements Thanks to Chris Provis and three anonymous reviewers at Philosophical Studies for their helpful comments on earlier versions of this paper.

Funding Open Access funding enabled and organized by CAUL and its Member Institutions

Open Access This article is licensed under a Creative Commons Attribution 4.0 International License, which permits use, sharing, adaptation, distribution and reproduction in any medium or format, as long as you give appropriate credit to the original author(s) and the source, provide a link to the Creative Commons licence, and indicate if changes were made. The images or other third party material in this article are included in the article's Creative Commons licence, unless indicated otherwise in a credit line to the material. If material is not included in the article's Creative Commons licence and your intended use is not permitted by statutory regulation or exceeds the permitted use, you will need to obtain permission directly from the copyright holder. To view a copy of this licence, visit http://creativecommons.org/ licenses/by/4.0/.

\section{References}

Andrighetto, G., Grieco, D., et al. (2015). Perceived legitimacy of normative expectations motivates compliance with social norms when nobody is watching. Frontiers in Psychology, 6(1413), 1-17

Bentham, J. (1978/1802). Principles of the Civil Code. Property: Mainstream and Critical Positions. C. B. Macpherson. Toronto, University of Toronto: 39-58

Bentham, J. (2013/1795). Jeremy Bentham's Economic Writings: Volume One London. Routledge 
Boran, I. (2016). Benefits, Intentions, and the Principle of Fairness. Canadian Journal of Philosophy, $36(1), 95-115$

Breakey, H. (2011). Two Concepts of Property: Ownership of Things and Property in Activities. The Philosophical Forum, 42(3), 239-265

Breakey, H. (2018). Same duties, different motives: Ethical theory and the phenomenon of moral motive pluralism. Philosophical Studies, 175(2), 531-552

Brown, A. (2012). Rawls, Buchanan, and the Legal Doctrine of Legitimate Expectations. Social Theory and Practice, 38(4), 617-644

Brucker, D. (2009). In defense of adaptive preferences. Philosophical Studies, 142, 307-324

Burgoon, J. K. (1993). Interpersonal expectations, expectancy, expectancy violations, and emotional communication. Journal of Language and Social Psychology, 12, 30-48

Castelfranchi, C. (2005). Mind as an Anticipatory Device: For a Theory of Expectations. Brain, Vision and Artifical Intelligence. M. D. Gregorio, V. D. Maio, M. Frucci and C. Musio.Naples, Springer:258-276

Castelfranchi, C., Giardini, F., et al. (2003). "The Prescriptive Destiny of Predictive Attitudes: From Expectations to Norms via Conventions." Proceedings of the Annual Meeting of the Cognitive Science Society 25: 222-227

Cross, R., \& Harris, J. (1991). Precedent in English Law. Oxford: Clarendon

Dana, J., Cain, D., et al. (2006). What you don't know won't hurt me: Costly (but quiet) exit in dictator games. Organizational Behavior and Human Decision Processes, 100, 193-201

Ellickson, R. (1993). "Property in Land.“. Yale Law Journal, 102, 1315-1400

Elster, J. (1982). Sour Grapes-Utilitarianism and the genesis of wants. Utilitarianism and Beyond. A. Sen and B. Williams. Cambridge, Cambridge: 219-238

Formosa, P. (2017). Kantian Ethics, Dignity and Perfection. Cambridge: Cambridge University Press

Fuller, L. (1969). The Morality of Law. New Haven: Yale University Press

Gur, N. (2013). Actions, Attitudes, and the Obligation to Obey the Law. The Journal of Political Philosophy, 21(3), 326-346

Harpine, W. (1993). The Appeal to Tradition: Cultural Evolution and Logical Soundness. Informal Logic, 15(3), 209-219

Heintz, C., Celse, J., et al. (2015). Facing expectations: Those that we prefer to fulfil and those that we disregard. Judgment \& Decision-Making, 10(5), 442-455

Irwin, K., \& Simpson, B. (2013). Do Descriptive Norms Solve Social Dilemmas? Conformity and Contributions in Collective Action Groups. Social Forces, 91(3), 1057-1084

Kant, I. (1785/2008). The moral law: Groundwork of the Metaphysic of Morals. New York, Hutchinson's University Library

Kershnar, S. (2014). A Promissory Theory of the Duty to Tip. Business and Society Review, 119(2), 247-276

Lewis, D. (2002/1969). Convention. Oxford: Blackwell

MacIntyre, A. (1981). After Virtue: A Study in Moral Theory. London: Duckworth

Miceli, M., \& Castelfranchi, C. (2002). The Mind and the Future: The (Negative) Power of Expectations. Theory \& Psychology, 12(3), 335-366

Michael, J., \& Székely, M. (2018). The Developmental Origins of Commitment. Journal of Social Philosophy, 49(1), 106-123

Milgram, S. (1963). Behavioral Study of Obedience. Journal of Abnormal and Social Psychology, 67(4), 371-378

Mill, J. S. (1859/2003). On Liberty. Hackett: Cambridge

Mill, J. S. (1861/2001). Utilitarianism. Hackett: Cambridge

Nussbaum, M. (2001). Adaptive Preferences and Women's Options. Economics and Philosophy, 17, 67-88

Olberding, A. (2016). Etiquette: A Confucian Contribution to Moral Philosophy. Ethics, 126, $422-446$

Provis, C. (2011). Individuals, Groups, and Business Ethics. London: Routledge

Provis, C. (2015). Confucianism, Virtue, and Wisdom. Handbook of Virtue Ethics in Business and Management. A. Sison. Dordrecht, Springer

Rawls, J. (1971). A Theory of Justice. Mass, Harvard: Cambridge

Ross, D. (2002/1930). The Right and the Good. Oxford: Oxford University Press

Salomon, A. (2021). "Contractualism and the question of direction."European Journal of Philosophy

Sampford, C. (1994). Law, Ethics and Institutional Reform: Finding Philosophy, Displacing Ideology. Griffith Law Review, 1(1), 1-38

Scanlon, T. (1990). Promises and Practices. Philosophy \& Public Affairs, 19(3), 199-226

Scanlon, T. M. (1998). What We Owe to Each Other. London Belknap Press 
Seigel, J. (2005). The idea of the self: Thought and experience in western Europe since the seventeenth century. New York: Cambridge University Press

Theriault, J. E., Young, L., et al. (2021). The sense of should: A biologically-based framework for modeling social pressure. Physics of Life Reviews, 36, 100-136

Tummolini, L., Andrighetto, G., et al. (2013). "A convention or (tacit) agreement betwixt us: on reliance and its normative consequences."Synthese(190):585-618

van der Vossen, B. (2015). Imposing Duties and Original Appropriation. The Journal of Political Philosophy, 23(1), 64-85

Vanberg, C. (2008). Why do people keep their promises? An experimental test of two explanations. Econometrica, 76(6), 1467-1480

Waldron, J. (1998). "The normative resilience of property.“. Otago Law Review, 9(2), 195-220

Whitehead, A. N. (1911). An Introduction to Mathematics. New York: Henry Holt \& Company

Publisher's Note Springer Nature remains neutral with regard to jurisdictional claims in published maps and institutional affiliations. 